\title{
Multiple Breath Washout Becoming Feasible for the Assessment of Lung Function in Infants and Young Children with Cystic Fibrosis in a Clinical Setting
}

\author{
Felix J.F. Herth \\ Department of Pneumology and Critical Care Medicine, Thoraxklinik University of Heidelberg, Heidelberg, Germany
}

Chronic obstructive lung disease has still the greatest impact on morbidity and mortality of patients with cystic fibrosis (CF). A series of recent studies in infants with CF who were diagnosed early by newborn screening demonstrated that CF lung disease starts already in the first months of life, mostly without any respiratory symptoms [1-3]. Therefore, sensitive noninvasive outcome measures are needed to detect early alterations and monitor lung disease in non-cooperative infants and young children with CF. The multiple breath washout (MBW) technique has been shown to be sensitive in the detection of alterations in the small airways [4-6], i.e. the airway region where $\mathrm{CF}$ lung disease is thought to originate. The most widely used parameter determined by MBW is the lung clearance index that reflects the number of lung turnovers necessary to clear a tracer gas from the lung and thus the severity of ventilation inhomogeneity. MBW has already been used for the assessment of lung function in older and cooperative children with CF in the clinical setting. However, MBW measurements in infants and young uncooperative children have so far only been performed at a limited number of specialized centers and with specialized equipment.

In the current issue of Respiration, Stahl et al. [7] report data on the feasibility of MBW measurements ob- tained with commercially available equipment in infants and young children in a center that had no prior expertise in this technique. As assessment of lung function by spirometry is not feasible in the first years of life, $\mathrm{MBW}$ is an attractive alternative approach because it does not require forced expiratory maneuvers and can be performed in spontaneously breathing children, either awake or sleeping, from the first months of life. To explore the feasibility of MBW in the clinical setting, the authors studied children below the age of 4 years with $\mathrm{CF}$ and a control group without lung disease during a routine visit. After an initial learning curve, they report highly acceptable success rates of $\sim 90 \%$ of MBW studies with at least one successful washout and $75 \%$ with two successful washouts. These results support that MBW measurements with commercially available equipment are feasible for monitoring of lung function during routine clinical workup in this young age group. Furthermore, the results confirm that MBW measurements are a sensitive tool to detect differences in the lung clearance index between the $\mathrm{CF}$ and control groups with relatively small group size and to identify individual CF patients with early abnormalities in lung function.

To our knowledge, this is the first study demonstrating the feasibility of MBW in the clinical setting in small chil-

\section{KARGER}

E-Mail karger@karger.com

www.karger.com/res
(C) 2014 S. Karger AG, Basel

0025-7931/14/0875-0353\$39.50/0
Prof. Dr. Felix J.F. Herth

Department of Pneumology and Critical Care Medicine

Thoraxklinik University of Heidelberg, Amalienstrasse 5

DE-69126 Heidelberg (Germany)

E-Mail felix.herth@med.uni-heidelberg.de 
dren $(<4$ years of age). The high success rate of technically acceptable measurements after a short training period in a center without prior experience with MBW is important and encouraging information for centers that are planning to use this technique for diagnostic monitoring of early lung disease in CF, as well as for investigators seeking noninvasive endpoints for multicenter early intervention trials in CF.

In this context, clinical testing of the efficacy of the symptomatic therapies that are established for older patients with CF was hampered by the lack of established outcome parameters in infants and young children and the preventive potential of these symptomatic treatments remains unclear. MBW is a promising method to close this diagnostic gap, and first pilot trials using this technique were able to detect response to therapy in young children, even when established parameters like forced expiratory volume in $1 \mathrm{~s}$ failed to show therapeutic effects [8-10]. With the CFTR modulator ivacaftor (VX-770), the era of causal CF therapy has started, at least for patients with the G551D mutation. In the near future, the use of quantitative noninvasive endpoints that are sensitive to detect even small treatment effects due to a better initial status of young CF patients will be essential to explore the effects of preventive treatment with CFTR mod- ulators in clinical trials [11]. The work by Stahl et al. [7] further supports the feasibility of MBW as an outcome measure in early CF lung disease and indicates that it is feasible to use standardized MBW measurements with a commercially available device for multicenter clinical trials in patients with early CF lung disease.

The paper by Stahl et al. [7], however, also has some limitations. First, the number of children with $\mathrm{CF}$ and age-matched controls was small and the results need to be validated in a multicenter setting. Nevertheless, the authors were able to detect a significantly higher lung clearance index in their CF population compared to the control group, indicating that this method may be sensitive to detect therapeutic responses in individual patients and small study populations. Second, the use of sulfur hexafluoride, a greenhouse gas, for MBW is not desirable; however, up to now, there is no alternative for standardized washout measurements in the young age group studied by Stahl et al. [7].

In conclusion, the study gives an encouraging outlook for the use of MBW for diagnostic monitoring of lung function in young CF patients in a clinical care setting, as well as in clinical trials investigating early CF lung disease and preventive therapies.

\section{References}

1 Sly PD, Brennan S, Gangell C, de Klerk N, Murray C, Mott L, Stick SM, Robinson PJ, Robertson CF, Ranganathan SC: Lung disease at diagnosis in infants with cystic fibrosis detected by newborn screening. Am J Respir Crit Care Med 2009;180:146-152.

-2 Belessis Y, Dixon B, Hawkins G, Pereira J, Peat J, MacDonald R, Field P, Numa A, Morton J, Lui K, Jaffe A: Early cystic fibrosis lung disease detected by bronchoalveolar lavage and lung clearance index. Am J Respir Crit Care Med 2012;185:862-873.

3 Hoo AF, Thia LP, Nguyen TT, Bush A, Chudleigh J, Lum S, Ahmed D, Lynn IB, Carr SB, Chavasse RJ, Costeloe KL, Price J, Shankar A, Wallis C, Wyatt HA, Wade A, Stocks J: Lung function is abnormal in 3-month-old infants with cystic fibrosis diagnosed by newborn screening. Thorax 2012;67:874-881.

4 Aurora P, Bush A, Gustafsson P, Oliver C, Wallis C, Price J, Stroobant J, Carr S, Stocks J: Multiple-breath washout as a marker of lung disease in preschool children with cystic fibrosis. Am J Respir Crit Care Med 2005;171: 249-256.
5 Ellemunter H, Fuchs SI, Unsinn KM, Freund MC, Waltner-Romen M, Steinkamp G, Gappa M: Sensitivity of lung clearance index and chest computed tomography in early CF lung disease. Respir Med 2010;104:1834-1842.

6 Gustafsson PM, Aurora P, Lindblad A: Evaluation of ventilation maldistribution as an early indicator of lung disease in children with cystic fibrosis. Eur Respir J 2003;22:972-979.

-7 Stahl M, Joachim C, Blessing K, Hämmerling S, Sommerburg O, Latzin P, Mall MA: Multiple breath washout is feasible in the clinical setting and detects abnormal lung function in infants and young children with cystic fibrosis. Respiration 2014;87:357-363.

-8 Amin R, Subbarao P, Jabar A, Balkovec S, Jensen R, Kerrigan S, Gustafsson P, Ratjen F: Hypertonic saline improves the LCI in paediatric patients with CF with normal lung function. Thorax 2010;65:379-383.
Amin R, Subbarao P, Lou W, Jabar A, Balkovec $S$, Jensen R, Kerrigan S, Gustafsson $P$, Ratjen F: The effect of dornase alfa on ventilation inhomogeneity in patients with cystic fibrosis. Eur Respir J 2011;37:806-812.

10 Subbarao P, Stanojevic S, Brown M, Jensen R, Rosenfeld M, Davis S, Brumback L, Gustafsson P, Ratjen F: Lung clearance index as an outcome measure for clinical trials in young children with cystic fibrosis: a pilot study using inhaled hypertonic saline. Am J Respir Crit Care Med 2013;188:456-460.

11 Ramsey BW, Banks-Schlegel S, Accurso FJ, Boucher RC, Cutting GR, Engelhardt JF, Guggino WB, Karp CL, Knowles MR, Kolls JK, LiPuma JJ, Lynch S, McCray PB Jr, Rubenstein RC, Singh PK, Sorscher E, Welsh M: Future directions in early cystic fibrosis lung disease research: an NHLBI workshop report. Am J Respir Crit Care Med 2012;185:887892. 